\title{
A Clinical Study of Complicated Inguinal Hernia with Special Reference to Its Management
}

\author{
Pulin Ch Kumar', Paul Pratik ${ }^{2}$ \\ ${ }^{1}$ Associate Professor, ${ }^{2}$ PGT, Department of General Surgery, Gauhati Medical College and Hospital, \\ Guwahati, Assam
}

\begin{abstract}
Introduction: The complications of hernias are incarceration, strangulation, and bowel obstruction. The reasons for the simple hernia to go into complications are of manyfold including lack of public awareness of the dangers of hernia complications, etc. Therefore, evaluating the high-risk causes of the complicated inguinal hernia and its effective management is very important in clinical practice. Materials and methods: It was a hospital-based prospective observational study. Results: The complicated inguinal hernia was observed with a male and female ratio of $24: 1$ and highest $(30 \%)$ frequency in the age group of 50-60 years. The right-sided involvement was seen in 33(66\%) cases with more features of strangulation. The primary and recurrent hernia was observed in $48(96 \%)$ and $2(4 \%)$ cases respectively. Complications are more in 35(70 $\%)$ cases with a short duration $(<1 \mathrm{yr})$. The pain and irreducible groin swelling were seen in all $50(100 \%)$ of cases. Viability of content as per intraoperative finding where gangrenous/strangulated bowel was found in $18(36 \%)$ cases. Reduction and Hernioplasty was done in 28(56) of cases. Conclusion: A systematic evaluation of clinical features with early intervention help in the management of the cases effre3ctively to reduce mortality and morbidity.
\end{abstract}

Keywords: Pain; time lapsed; gangrenous resection anastomosis; herniorrhaphy.

\section{Introduction}

A hernia is a protrusion of a viscus or part of a viscus through an abnormal opening in the walls of its containing cavity. ${ }^{1}$

Seventy-five per cent of all abdominal wall hernias are found in the groin, making it the most common location for an abdominal wall hernia. Of all groin hernias, $95 \%$ are the hernias of the inguinal canal with the remaining being femoral hernia defects. Inguinal hernias are nine times more common in men than in women. The overall lifetime risk of developing a groin hernia is approximately $15 \%$ in males and less than

\section{Corresponding Author: \\ Pulin Ch Kumar}

Associate Professor, Email: drpulinkr@gmail.com Mobile: +919864032323, PGT, Department of General Surgery, Gauhati Medical College and Hospital, Guwahati, Assam
$5 \%$ in females. Inguinal hernias are further divided by anatomical location into direct and indirect types. This differentiation is based on the location of the actual hernia defect concerning the inferior epigastric vessels. ${ }^{2}$ Indirect inguinal hernias strangulate more commonly, the direct variety not so often because of the wide neck of the sac. ${ }^{1}$

There is an association between age and hernia diagnosis. After an initial peak in the infant, groin hernias become more prevalent with advancing age. In the same way, the complications of hernias (incarceration, strangulation, and bowel obstruction) are found more commonly at the extremes of age. ${ }^{2}$

The reasons for the simple hernia to go into complications include lack of public awareness of the dangers of hernia complications and reluctance on behalf of the non-surgical medical personnel to refer patients with known risk factors. ${ }^{3}$ 
An inguinal hernia either direct and indirect is one of the most common problems that we face in our routine surgical practice and uncomplicated hernia possess no difficulty so far as many advances are present for the repair of the defect. Management of these complicated hernias is different from uncomplicated hernias. Most important is the morbidity and mortality associated with this hernias. ${ }^{4}$

This paper aims to find out the high-risk factors for the development of the complicated inguinal hernia and also to find out effective management of the operated patients.

\section{Materials and Method}

It was a prospective observational study. The study consists of 50 cases undergone surgery for complicated inguinal hernia in various surgical units in Gauhati Medical College and Hospital, Guwahati, Assam during the period July $1^{\text {st }} 2017$ to June $30^{\text {th }} 2018$. The study was conducted among patients admitted from casualty with the complaint of a groin swelling and associated features of its complication, who were of age above 12 years and with the unilateral hernia. Before collection of the data ethical approval was obtained from the ethics committee (Human).

\section{Results}

In our present study, we found that out of the 50 patients of complicated inguinal hernia involved dominantly the male population (96\%) as compared to females $(4 \%)$ giving a male and female ratio of $24: 1$ as shown in Fig. 1.

\section{Fig. 1 Sex-wise inguinal hernia patients}

Out of 50 patients maximum cases, (30\%) presented complicated Hernia that falls under the age group (50$60)$ years and very less number of cases below 20 years (Fig. 2).

Fig. 2 Distribution of inguinal hernia patients according to age

The present study reveals that inguinal hernias more common on right side $33(66 \%)$ than that in left side $17(34 \%)$. Right-sided hernias tend more to present with features of strangulation than left side; $p<.0448$ which is statistically significant. We have also found that $48(96 \%)$ of patients had a primary hernia and only $2(4 \%)$ had a recurrent hernia. The hernias with a short duration $(<1 \mathrm{yr})$ were those who mostly developed the highest rate of complications with 35 cases (70\%).

Table 1 Symptoms of complications

\begin{tabular}{|l|l|l|}
\hline Symptoms & No. of patients & Percentage \\
\hline Pain & 50 & 100 \\
\hline Irreducible Groin Swelling & 50 & 100 \\
\hline Vomiting & 32 & 64 \\
\hline Absolute Constipation & 30 & 60 \\
\hline Fever & 10 & 20 \\
\hline
\end{tabular}

In our study, pain and irreducible groin swelling were seen in all $50(100 \%)$ of cases. Details are shown in

Table 1.: The three categories, i.e., irreducible, obstructed and strangulated inguinal hernia based on relevant clinical symptoms and signs are shown in Table 2 with their frequencies.

Table 2 Clinical presentation

\begin{tabular}{|l|l|l|}
\hline Presentation & No. of patients & Percentage \\
\hline $\begin{array}{l}\text { Irreducibility/ } \\
\text { Incarceration }\end{array}$ & 20 & 40 \\
\hline Obstructed & 18 & 36 \\
\hline Strangulation & 12 & 24 \\
\hline
\end{tabular}

Viability of content as per intraoperative finding where gangrenous/strangulated bowel was found in $18(36 \%)$ of the total cases as shown in Table 3.

Table 3 Viability of content as per intraoperative finding

\begin{tabular}{|l|l|l|l|}
\hline \multirow{2}{*}{ Status of Content } & \multicolumn{3}{|c|}{ Contents } \\
\cline { 2 - 4 } & Bowel & Omentum & Total \\
\hline Viable & $19(38 \%)$ & $10(2 \%)$ & 29 \\
\hline Gangrenous & $18(36 \%)$ & $3(6 \%)$ & 21 \\
\hline Total & $37(74 \%)$ & $13(26 \%)$ & 50 \\
\hline
\end{tabular}


It has been found that among the 28 patients who presented $>24 \mathrm{hrs}$ after onset of symptoms $17(60.71 \%)$ had gangrenous changes of bowel requiring resection, compared to 9 patients who presented $<24 \mathrm{hrs}$ where the resection rate is $11.11 \%(\mathrm{p}-<0.0188)$ as shown in Table 4.

Table 4 Time elapsed from the onset of symptoms \& presentation and the status of bowel intraoperatively

\begin{tabular}{|l|l|l|l|}
\hline Time elapsed & $\begin{array}{l}\text { Viable bowel (not requiring } \\
\text { resection) }\end{array}$ & $\begin{array}{l}\text { Gangrenous bowel (requiring } \\
\text { resection) }\end{array}$ & Total \\
\hline$<24 \mathrm{Hrs}$ & 8 & $1(11.11 \%)$ & 9 \\
\hline$>24 \mathrm{Hrs}$ & 11 & $17(60.71 \%)$ & 28 \\
\hline TOTAL & 19 & 18 & 37 \\
\hline
\end{tabular}

The evaluation of the result shows that the majority $(90 \%)$ of complicated inguinal hernia is indirect and the rest $(10 \%)$ are the direct hernia.

The details operative procedures undertaken were shown in Table 5.

Table 5 Operative Procedure performed

\begin{tabular}{|l|l|}
\hline Procedure Performed & Number (\%) \\
\hline Reduction and Hernioplasty & $28(56)$ \\
\hline Omentectomy and Herniorrhaphy & $3(6)$ \\
\hline Resection of Bowel with Herniorrhaphy & $16(32)$ \\
\hline Resection of bowel with Stoma formation with Herniorrhaphy & $2(4)$ \\
\hline Appendicectomy with Herniorrhaphy & $1(2)$ \\
\hline Total & $50(100)$ \\
\hline
\end{tabular}

\section{Discussion}

The male and female ratio (24:1) in the current study among the complicated of inguinal hernia in the present study is in the consistency of Hariprasad et al. ${ }^{\mathbf{5}}$

This finding of ours was following that of the study done by Hariprasad et al. ${ }^{5}$, where the author observed that the majority $(22.5 \%)$ of patients with complicated inguinal hernia presented in $5^{\text {th }}-6^{\text {th }}$ decade of life.

The right-sided hernias tend more to present with features of strangulation than left-sided hernias ( $p<$ .0448). These findings are in concordance with S Rai et al., ${ }^{3}$ NJ Andrews et al., ${ }^{6}$ Hariprasad et al., ${ }^{5}$ and Prakash JS. $^{7}$

The hernias (70\%) presented with complication did so within 1 year of duration. This finding was following the result of the study done by S Rai et al. ${ }^{3}$ where the author described that short duration of a hernia was found to be a very significant risk factor which predicted complication. The author noted that the majority of adults with complicated hernias $(65.8 \%)$ had the hernia for a duration less than or equal to 1 year $(\mathrm{p}-<0.05)$.

The primary hernias were observed in $96 \%$ of patients and the rest $4 \%$ were the recurrent hernia. 
The type of hernia also affects the viability of content, especially recurrent hernias. In our study, there were 2 recurrent hernias and both of the cases had gangrenous contents and needed resection. S Rai et al., ${ }^{3}$ also noted a similar finding in his study where all 4 cases of recurrent hernia underwent resection and the author have regarded recurrent hernias to be susceptible to strangulation. NJ Andrews et al., ${ }^{6}$ also observed that risk of strangulation in recurrent hernia is more as compared to primary hernias, the increased risk has been attributed to their having narrow irregular defects with unyielding walls; the author also concluded that strangulated recurrent hernias were associated with high morbidity and mortality.

In the current study, pain and irreducible groin swelling were seen in all 50(100\%) of cases; vomiting was seen in $32(64 \%)$ cases while absolute constipation was seen in 30(60\%) cases and fever was present in 10 (20\%) cases. Similarly, Manish Baria et al., ${ }^{4}$ in their study has observed that pain and irreducible hernia swelling was present in all the cases (100\%), 30\% of patients had nausea, vomiting, constipation and abdominal distension was present in $20 \%$ of cases each.

Incidence rates of symptoms obtained by Prakash JS et al., ${ }^{7}$ in their study also shows a similar pattern, pain and irreducibility in $100 \%$ of cases, vomiting in $82.8 \%$, abdominal distension in $80 \%$, constipation in 74.35 and fever in $25.7 \%$ cases. Hariprasad et al., ${ }^{\mathbf{5}}$ in their study have observed similar findings. Irreducibility of the hernia swelling, absent cough impulse and local tenderness were seen in all 50(100\%) cases; abdominal tenderness was seen in $30(60 \%)$ of cases while abdominal muscle guarding and absent bowel sound was observed in $18(36 \%)$ of cases. Similar results are obtained by Hariprasad et al., ${ }^{\mathbf{5}}$ and Muhammad Hasan Abbas et al. ${ }^{\mathbf{8}}$

Signs of peritonitis which predict strangulation significantly among other clinical features were observed which agree Muhammad Hasan Abbas et al. ${ }^{\mathbf{8}}$ The author stated that in the absence of obvious peritonitis, clinical signs cannot reveal the condition of incarcerated bowel. There may be speculation based on the duration of symptoms and hernia type but the only safe management is early operation after necessary resuscitation as stated by NJ Andrews et al., ${ }^{6}$
The results report that $40 \%$ of cases presented with painful irreducibility; $36 \%$ of patients presented with features of obstruction, and $24 \%$ cases with features of strangulation which agrees Manish Baria et al. ${ }^{4}$

A total of 28 patients who presented 24 hours after the onset of symptoms, 17(60.71\%) cases developed gangrenous changes of bowel requiring resection which is in support of Hariprasad et al., ${ }^{\mathbf{5}}$ and Kulah B et al. ${ }^{\mathbf{9}}$

Viability of the contents in complicated hernias correlated significantly with the delay in presentation; The greater the delay, greater the risk for strangulation. ${ }^{3}$ Martinez-Serrano et al., ${ }^{\mathbf{1 0}}$ revealed higher rates of mortality in patients with acute complication as their first hernia related symptom and whose treatment was delayed for more than 24 hours.

Thus in 36\% cases, general anaesthesia was given and $64 \%$ cases spinal was given. All cases where strangulation was suspected and peritonitis were there general anaesthesia was preferred where there was a strong suspicion of strangulation. These findings are following Brindelli et al., ${ }^{11}$ and Rene E Stoppa, ${ }^{12}$

The higher frequency of indirect inguinal hernias of the current study agrees Hariprasad et al. ${ }^{5}$ The viability of contents of the current study are in support of Hariprasad et al. ${ }^{5}$

In the current study, 18 cases had gangrenous bowel as content requiring resection, 16 underwent resection with herniorrhaphy and 2, resection with a stoma with herniorrhaphy. 28 cases where the content was viable underwent reduction and hernioplasty as the surgical field was clean and hernioplasty prevents recurrence; 3 cases where the omentum was necrotic, omentectomy with herniorrhaphy was done; in one case there was inflamed appendix as content so appendicectomy with herniorrhaphy was done. The surgical procedures undertaken agree with Manish Baria et al., ${ }^{4}$ and Rives et al. ${ }^{13}$

\section{Conclusion}

Elderly age group is most susceptible for development of hernia complications with a higher frequency in male. Right-sided hernias develop more complications. Direct hernias are much less affected than indirect hernias. 
Hernia of short duration is also found to be more prone to develop complications. Recurrent cases had gangrenous content and needed resection. Pain and irreducibility of groin swelling were the most common presenting symptoms, other being vomiting, absolute constipation and fever. The signs of peritonitis including muscle rigidity and absent bowel sound predictive of strangulation.

The raised total leukocyte count was found to be significantly predictive of strangulation. Spinal anaesthesia was preferred. All cases where bowel was gangrenous resection anastomosis was done followed by herniorrhaphy (Bassini); similarly, in cases with gangrenous omentum omentectomy with herniorrhaphy was done. Cases, where the content was the viable reduction of the content and Lichtenstein tension free hernioplasty, was done. The outcome of $70 \%$ of cases in this study went uneventful, $10 \%$ of cases developed wound infection.

Ethical Clearance: Taken.

Conflict of Interest: None declared.

Source Of Funding: None declared.

\section{References}

1. Andrew N Kingsnorth, Giorgi Giorgobiam, David $\mathrm{H}$ Bennett. Hernias, umbilicus and abdominal wall. In: Norman S Williams, Christopher JK Bulstrode, $\mathrm{P}$ Ronan O'Connell, editors. Bailey and love's short practice of surgery. $25^{\text {th }}$ ed. London: Hodder Arnold Ltd; 2008. p. 968-990.

2. Patrick J Javid, Jacob A Greenberg, David C Brooks. Hernias. In: Michael J Zinner, Stanley W Ashley, editors. Maingot's abdominal operations. $12^{\text {th }}$ ed. McGraw Hill Education; 2013. p. 123-156.

3. Rai S, Chandra SS, Smile SR. A study of the risk of strangulation and obstruction in groin hernias. Australian and New Zealand journal of surgery 1998 Sep;68(9):650-4.

4. Manish Baria, Ankit Parmar. A clinical study on the management of complicated inguinal hernias.
International Journal of Scientific Research 2014;3:387-389.

5. Hariprasad S, Srinivas T. Clinical study on complicated presentations of groin hernias. International Journal of Research in Medical Sciences. 2017 Jul 26;5(8):3303-8.

6. Andrews NJ. Presentation and outcome of strangulated external hernia in a district general hospital. British Journal of Surgery 1981 May;68(5):329-32.

7. Prakash S, Samraj A, Muthukumaran G. A study on groin hernias presenting as acute surgical emergencies in adults. International Surgery Journal. 2017 Nov 25;4(12):3866-72.

8. Abbas $\mathrm{MH}$. Outcome of strangulated inguinal hernia. Pakistan Journal of Medical Sciences 2005 Oct;21(4):445.

9. Kulah B, Duzgun AP, Moran M, Kulacoglu IH, Ozmen MM, Coskun MF. Emergency hernia repairs in elderly patients. The American journal of surgery 2001 Nov 1;182(5):455-9.

10. Martínez-Serrano MA, Pereira JA, Sancho J, Argudo N, López-Cano M, Grande L. Specific improvement measures to reduce complications and mortality after urgent surgery in complicated abdominal wall hernia. Hernia 2012 Apr 1;16(2):171-7.

11. Birindelli A, Sartelli M, Di Saverio S, Coccolini F, Ansaloni L, van Ramshorst GH, Campanelli G, Khokha V, Moore EE, Peitzman A, Velmahos G. 2017 update of the WSES guidelines for emergency repair of complicated abdominal wall hernias. World Journal of Emergency Surgery 2017 Dec;12(1):37.

12. Stoppa RE. The treatment of complicated groin and incisional hernias. World journal of surgery 1989 Sep 1;13(5):545-54.

13. Rives J, Stoppa R, Fortesa L, Nicaise H. Les pieces en Dacron et leur place dans la chirurgie des hernies de l'aine. Ann Chir 1968;22(3-4):159-71. 